\title{
Uber, superexploração do trabalho e o capitalismo de plataforma em contexto de pandemia: novas e velhas formas de controle e resistência
}

\author{
Gil Felix ${ }^{1}$
}

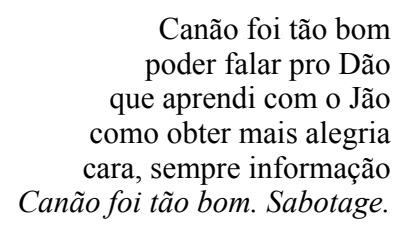

\section{Introdução}

Para certa ideologia hegemônica do mercado, em tese, acelerar e ampliar a circulação das mercadorias acarretaria transformações profundas do tempo e do espaço, mas não maiores contradições sociais. Uma interpretação a partir da teoria marxiana do valor trabalho, como a que eu venho pesquisando (Felix, 2018; 2019; 2020), permite hipótese no sentido oposto. A reprodução social do trabalhador pode vir a ser profundamente alterada em termos de espaço e tempo e, também, profundamente dilapidada, inclusive, e justamente, por meio das próprias "leis de mercado" ao vender a sua força-de-trabalho.

O "trabalho", que é considerado pela gestão empresarial moderna um "serviço" que deve ser adquirido pelo menor preço no mercado, usado da forma a mais intensa possível e substituído sempre que não é mais necessário ou rentável por outro melhor, ou seja, que é uma “coisa” como qualquer outra, elemento rentável ou peça, obviamente, tem implicações diferentes para seu vendedor. Este é o caso do/as trabalhadores/as diretamente subordinados ao chamado "capitalismo de plataforma" e, em particular, dos entregadores e motoristas da empresa Uber que alcançaram grande visibilidade pública nos últimos anos no Brasil e em diversos outros países. Dada sua rápida expansão e as mobilizações realizadas desde o advento da pandemia de COVID-19, o debate que já estava em curso entre especialistas do mundo do trabalho vem sendo ampliado a outros âmbitos sociais e se insere na agenda pública das organizações sindicais da classe trabalhadora, dos partidos, de organismos internacionais e das mídias jornalísticas e políticas de maneira geral.

\footnotetext{
1 Cientista social. Professor da Universidade Federal da Integração Latino-americana (UNILA). Coordenador do Grupo de Pesquisa sobre Trabalho (CNPq). www.grupodepesquisasobretrabalho.wordpress.com . Email: gilfelix@protonmail.com . Orcid: https://orcid.org/0000-0001-8371-1358
} 
Neste sentido, dando continuidade a pesquisas anteriores e a outras em desenvolvimento, abordarei alguns aspectos do estudo de caso das condições de trabalho desses/as trabalhadores/as e das formas de controle e de resistência que estão sendo empregadas por eles/as, nacional e internacionalmente ${ }^{2}$.

\section{O que há de novo?}

Nas economias centrais, a erosão da condição operária comumente associada ao fordismo que teria caracterizado as estratégias produtivas da indústria desses países em grande parte do século XX estaria motivando abordagens a respeito de um "retorno da superexploração" (Harvey, 2008), da crise da "sociedade salarial" (Castel, 1998), emergência de um "precariado" (Standing, 2015) etc. Por outro lado, a desestatização das economias anteriormente planificadas também foi acompanhada de um amplo quadro de demissões e de implantação ou transformação dos processos de trabalho com base nessas mesmas estratégias pós-crise. Já nas formações sociais periféricas ou dependentes do capitalismo, em que, quando observada, tal condição pretérita abarcava apenas uma fração estatisticamente minoritária do próprio conjunto do operariado, processo específico, embora consonante, também vem sendo analisado sob diversos matizes. Sobre essas formações periféricas ou dependentes, porém, paira ainda enorme desconhecimento desse processo, tanto em termos empíricos quanto, especialmente, teóricos. Por questões que não serão ressaltadas aqui, mas que poderão ser deduzidas pelo/a leitor/a, cabe frisar que tais formações sociais apresentam cada vez melhor perspectiva para a observação dos processos mundiais em curso e, possivelmente, por conseguinte, também maior poder explicativo para a compreensão dos mesmos (Felix, 2021a; 2021b; Felix e Sotelo, $2019)^{3}$.

\footnotetext{
2 Além de outras pesquisas mais recentes e de diversas informações veiculadas a respeito desse setor, os dados aqui citados advêm do plano de trabalho "Estudo das condições de trabalho e dos trabalhadores da empresa UBER e similares", desenvolvido pelo Grupo de Pesquisa sobre Trabalho (CNPq) no âmbito do Projeto de Pesquisa "Trabalho e trabalhadores na América Latina e Caribe: economia, sociedade e política", que, sob minha coordenação e orientação na Universidade Federal da Integração Latino-americana (UNILA), participaram os estudantes Wilson Antonio de Almeida Duarte, Welita Barbosa da Silva, Vitor Mateus Morais e Maurício Machado Lourenço.
}

\footnotetext{
3 Dado um quadro de deterioração, fragmentação ou mesmo degradação das condições de vida e trabalho dos trabalhadores de gerações anteriores, alguns autores têm se voltado para teorias outrora pensadas no âmbito das ciências sociais latino-americanas, que, particularmente a partir dos anos 1960, propuseram interpretações originais para a compreensão das formações sociais dos seus próprios países de forma crítica a epistemologias eurocêntricas e/ou nãosistêmicas do capitalismo mundial (Gunder Frank, 1964; Marini, 1973; 1974; 1978; Casanova, 2009; Nun, 2001; Cardoso de Oliveira, 1978). Pesquisadores como Gavin Smith (2011) e Soederberg (2013) tiveram referência em escritos do argentino Jose Nun. Outros, como Sotelo (1993; 2012) e John Smith (2016) abordaram tais tendências com base, dentre outros, nas últimas análises do brasileiro Ruy Mauro Marini (1993; 1996). Por fim, alguns, em sentido oposto, têm demonstrado haver um processo de emergência da categoria precariado sob diferentes enfoques, a partir da análise proposta pelo inglês Guy Standing (Alves, 2014; Braga, 2017; Antunes, 2018).
} 
Processos de mundialização e de reestruturação produtiva, assim como a expansão de fenômenos convencionalmente descritos nos estudos do trabalho como precarização e/ou flexibilização do trabalho, inseriram complexidades renovadas para os cientistas sociais especializados na área e, com elas, também, a necessidade de novas pesquisas a partir de contextos latino-americanos e mundiais.

Segundo o relatório da Organização Internacional do Trabalho intitulado "Changing nature of jobs" (ILO, 2015), por exemplo, há uma tendência mundial de crescimento, ou substituição, dos empregos de tempo integral e contrato estável de trabalho para as denominadas non-standard forms of employment. Analisando os padrões de emprego em mais de 180 países, a OIT constatou que trabalhos estáveis, de tempo integral, representam menos de um em cada quatro empregos e que “(...) uma continuação de tendências passadas sugere que a incidência de relações de trabalho estável formará uma fração ainda menor do total de empregos nos próximos anos”. (ILO, 2015: 5).

Em geral, essas tendências implicam necessárias revisitas teóricas e novos exercícios analíticos para os estudos do trabalho, a fim de dar conta de fenômenos em expansão mundial e que convencionalmente se designam, por exemplo, em vários países do mundo, como precarização, flexibilização, walmartização, mcdonaldização ou mesmo uberização do trabalho, junto à constatação de um crescente exército de reserva, certas vezes adjetivado global ou em mundialização (Chesnais, 2006; Magdoff; Magdoff, 2004; Foster; McChesney; Jonna, 2011; Smith, 2016; Felix, 2019). Já nos últimos anos e, em especial, no contexto pandêmico, as abordagens do que seria uma plataformização do trabalho vêm sendo intensamente pesquisadas e debatidas (ILO, 2018; Pesole et al., 2018; Abdelnour e Bernard, 2018; Huws et al., 2019; Chaves Jr. et al., 2021; Panicht e Albo, 2021).

Considerando as questões acima, uma categoria que assumiu enorme importância para se compreender as transformações em curso é a dos motoristas da empresa Uber e de trabalhadores de empresas de aplicativos para celulares em geral, que agregam tanto empresas transnacionais, como a própria Uber, Deliveroo, iFood etc, quanto empresas locais como a Garupa, por exemplo, utilizada em cidades do oeste do estado do Paraná. A Uber, porém, desponta atualmente não apenas como a maior dessas empresas, mas, para além disso, como referência de uma nova gestão do trabalho, radicalizando tendências já descritas na chamada reestruturação produtiva. Segundo as mídias sindicais, essa empresa já teria hoje mais de 2 milhões de motoristas em mais de 80 países no mundo ${ }^{4}$. Segundo dados divulgados pela empresa em sua página eletrônica no momento em que seu principal CEO à época visitou o país a fim de obter plena autorização legal para operar em reuniões com dirigentes do 
Parlamento e ministros de Estado, em 2017, seriam mais de 500 mil motoristas só no Brasil. É crível que esses dados tenham aumentado ainda mais no período pandêmico, tanto na Uber quanto nas demais empresas de entrega cujos serviços foram considerados essenciais e que são integradas principalmente por trabalhadores em situação de desemprego. Segundo os índices oficiais brasileiros e os monitoramentos globais feitos pela OIT no atual contexto, os índices de desemprego aumentaram para taxas históricas, como no caso, em especial, do Brasil e dos EUA, e os rendimentos dos trabalhadores foram reduzidos na maioria dos países observados (DIEESE, 2020a).

A partir disso, não são raros os exemplos em que as características do que seria uma uberização do trabalho também já estão sendo associadas a diversos outros setores econômicos e atividades laborais na educação, segurança, publicidade, saúde, hotelaria etc.

\section{Condições de visibilidade}

O contexto pandêmico evidenciou condições para que o chamado capitalismo de plataforma emergisse como questão pública e como temática acadêmica em disputa. Considerando que tal contexto foi utilizado pelas empresas para reduzir postos de trabalho, intensificar as tarefas, diminuir salários e rotacionar a força de trabalho - o que se verificou, por exemplo, no aumento dos índices oficiais de desemprego -, houve uma migração dos trabalhadores para algumas atividades comumente consideradas de vínculo temporário, cujas empresas, em geral, adotam recrutamento imediato. Contudo, além disso, também houve condições sociais de produção de visibilidade em virtude das desigualdades de classe, recrudescidas nesse contexto.

Serviços de empresas de aplicativos para celular que oferecem transporte de passageiros e de entrega de mercadorias vieram a ser mais comprados justamente por frações de classe que, por um lado, estiveram mais expostas aos meios de propagação midiática das recomendações sanitárias e que, por outro, vieram a adotar regimes de trabalho domiciliar ou remoto. Neste sentido, junto a outras categorias profissionais, os entregadores das empresas de aplicativos, em geral, sem organismos de representação sindical anteriormente consolidados, ganharam visibilidade nas áreas urbanas de maior poder aquisitivo, nas quais se concentram mais as compras e, da mesma forma, também se concentram os agentes sociais com maior poder de produção das agendas públicas hegemônicas e contrahegemônicas.

Em tais condições, as chamadas para as mobilizações e as denúncias das condições de trabalho e subsistência dos trabalhadores uberizados no Brasil tomaram grandes proporções, provocando uma ampla adesão social dos demais trabalhadores e das camadas médias. Para tanto, as formas e os meios 
por eles utilizados para a divulgação dessas denúncias também foram congruentes com tais condições, com o uso da internet. Porém, para além desses fatores, o principal fator de adesão tanto de cientistas sociais, analistas e demais comentadores profissionais ou amadores da sociedade quanto das demais frações de classe dos trabalhadores é o conteúdo expresso nas denúncias, particularmente, o sentido pelo qual as condições de trabalho apresentadas pelos trabalhadores dessas empresas de aplicativos também são cada vez mais amplamente percebidas socialmente pelas demais frações de trabalhadores ${ }^{5}$.

Isso porque tais condições de trabalho estão associadas à percepção social das demissões, do desemprego e da diminuição dos salários, assim como à similaridade com que as tecnologias utilizadas pela Uber e demais empresas de aplicativos também estão sendo cada vez mais empregadas nas demais empresas. Desde a sua plena regularização estatal no Brasil, a Uber ampliou a presença pública não apenas no mercado de trabalho, com a subordinação de milhares de novos motoristas, mas também no espaço público, com o uso massivo de propaganda. Desta forma, junto à sua expansão mundial e à valorização especulativa do seu preço de mercado nos últimos anos, essa empresa visa construir uma imagem futurista de referência para o que viria a ser uma moderna gestão do trabalho.

Por outro lado, as sucessivas reformas nas leis reguladoras do trabalho no Brasil foram realizadas a fim de dar maior liberdade para o agente patronal recrutar e demitir os trabalhadores, como foi o caso das terceirizações, instituída desde os anos 1990 e plenamente regularizada nos últimos anos, da Lei Geral da Micro e Pequena Empresa (ou "Super-simples") de 2007 e da reforma trabalhista promulgada em 2017, que, dentre outras modalidades, por exemplo, formalizou e instituiu o chamado trabalho intermitente. Neste modo, o agente patronal recruta e remunera o trabalhador apenas pelo período por ele mesmo solicitado, forma pela qual há similaridade essencial com a forma utilizada na Uber e demais empresas de aplicativos, conforme descreveremos a seguir. Sob tal modalidade formal de contrato, desde então, houve um crescimento desses vínculos tanto na indústria quanto nos serviços. Um levantamento realizado pela Confederação Nacional da Indústria feito com 523 indústrias indicou que $15 \%$ delas já empregam essa modalidade, sendo que a maioria das mesmas ampliou essa forma de contratação ${ }^{6}$. Por outro lado, segundo o DIEESE, o rendimento médio dos trabalhadores intermitentes contratados em geral foi de $\mathrm{R} \$ 637$, ou seja, cerca de 64\% do salário mínimo oficial. Em 2019, 22\% desses trabalhadores não tiveram nenhum rendimento (DIEESE, 2020b).

\footnotetext{
5 Embora não seja o objeto em questão aqui e tenhamos limitação no tamanho do texto para desenvolver tal adesão, considerando a ausência de alternativas voltadas para a defesa de seus interesses enquanto classe, é mister frisar que o sentido geral do isolamento político com que se deparam os trabalhadores no contexto atual também implica em uma adesão implicitamente solidária dos mesmos às reivindicações dessas novas categorias. Sobre isso, ver nota a respeito (Felix, 2020).
} 


\section{Condições de trabalho}

Nossas investigações mais recentes sobre os denominados peões-de-trecho - trabalhadores homens que se caracterizam por uma alta circulação mercantil da força de trabalho atrelada a uma intensa mobilidade espacial, em setores econômicos variados, tanto nos chamados rincões amazônicos quanto nas grandes cidades brasileiras - já apresentaram, heuristicamente, contribuições para a compreensão de aspectos teóricos e metodológicos para as pesquisas sobre algumas das principais características do que se denomina comumente como capitalismo de plataforma (Felix, 2019; 2021). Uma delas é a supercirculação, ou a extração de mais-valor baseada em um regime que acelera e amplifica a circulação mercantil da força-de-trabalho. E, por outro lado, a possível tendência à superexploração do trabalho, uma vez que há, em decorrência desse regime, aumento das jornadas, intensificação do trabalho e, ainda, diminuição das remunerações do trabalhador. Tal tendência, ao menos no caso dos motoristas da Uber, já tem sido observada pelas pesquisas mais recentes em curso, além de ter sido amplamente denunciada pelos entregadores nas suas últimas mobilizações.

Contudo, no caso da Uber, há o uso tecnológico de sistemas que permitem coincidir exatamente o tempo de compra da força-de-trabalho com o seu exato consumo no processo produtivo, isto é, só se remunera pelo período em que o motorista está efetivamente guiando e levando o cliente no perímetro adquirido por meio da plataforma. O tempo em deslocamento entre uma corrida e outra não é remunerado, e a remuneração, no "tempo de produção", é dada por uma fórmula algorítmica em que incidem fatores como demanda de novas compras, localização do motorista, tempo e distância de deslocamento no trânsito. Além disso, em sua quase totalidade, os motoristas estão conectados não apenas ao aplicativo da Uber, mas também a outros concorrentes similares. O resultado calculado pelos desenvolvedores desse sistema eletrônico é, justamente, um processo de dilapidação da força de trabalho dado pelo aumento do tempo de circulação (tempo de não venda) da mercadoria ao mesmo tempo em que aumenta o tempo de trabalho (horas de consumo). Não raro, as jornadas de trabalho desses motoristas são extensas, em geral, com mais de 10 horas ao dia. Muitos relataram fazer pequenas refeições no carro e, em grandes cidades, alguns relataram dormir algumas horas dentro dele, para não ter que voltar para suas casas que estariam longe das principais rotas e das melhores corridas oferecidas pelo aplicativo ${ }^{7}$.

\footnotetext{
7 Tal como nós verificamos, outras pesquisas também têm atestado resultados semelhantes para os demais trabalhadores vinculados a empresas de aplicativo no Brasil (NEC/UFBA, 2020). Junto com as pesquisas, diversos relatos jornalísticos ou depoimentos divulgados pelos próprios trabalhadores também relatam essas situações tanto no Brasil quanto em diversos outros países nos últimos anos.
} 
$\mathrm{Na}$ Uber e aplicativos similares, é necessário que o trabalhador disponha de instrumentos específicos de trabalho, especialmente, da habilitação, do celular, da rede de dados por internet e do veículo. Isso implica em uma miríade de arranjos, desde os trabalhadores demitidos e desempregados que tinham carros próprios e que, sem outras alternativas, conectam-se à Uber, até aqueles que alugam carros em pacotes promocionais específicos - às vezes oferecidos por uma associação entre a Uber e empresas de locação - ou que, de, maneira informal, alugam entre si e se revezam em turnos de vínculo no aplicativo. Certos casos, ocorrem cadeias de sublocação tal como era comum no ramo de taxi anteriormente, com pequenos e médios empresários que detêm dezenas ou centenas de carros e que os alugam para o uso na Uber. Nesta situação, o trabalhador paga pelo uso do carro semanalmente para o locador, o que faz com que sua jornada de trabalho tenha que ser ainda maior para aferir mais esse gasto.

Contudo, tal como se verificou nos últimos anos, o mesmo sistema de exploração do trabalho utilizado na Uber é empregado quando o trabalhador não dispõe desses instrumentos, podendo se conectar e fazer as entregas com o uso de uma bicicleta alugada por meio de um outro aplicativo ou até mesmo a pé, utilizando, nesse caso, somente o transporte público ou, o que é já comum em diversos países, correndo.

Apesar de alguns trabalhadores estabelecerem relações diretas e pessoais com os compradores e, eventualmente, estabelecerem alguma clientela fixa de venda dos seus serviços sem o uso do aplicativo, eles não dispõem dos meios de produção, no caso, do sistema, que é a única forma de acesso a entregas ou às corridas de maneira intermitente, porém, com a quantidade e a regularidade suficientes para alcançar uma remuneração minimamente necessária ou constante. No caso desses trabalhadores que dispõem de carros próprios, considerando as tarifas oferecidas pelas empresas e tendo eles mesmos que suportar as despesas de manutenção, combustível etc, o vínculo como motorista é precário e instável a ponto de, por exemplo, durar apenas o tempo ao longo do qual o trabalhador tem essa última poupança expropriada lentamente enquanto prolonga o tempo no desemprego. Para aqueles que se vincularam à Uber sem dispor anteriormente dessa poupança - ou que já a tiveram expropriada após esses primeiros vínculos sem sucesso em conseguir outro trabalho ou renda nesse período - geralmente há um percurso circular: o motorista pode vir a usar um veículo financiado, incluir o custo das parcelas de pagamento entre os demais gastos, aumentar a jornada de trabalho para isso e, em seguida, uma vez terminado o financiamento, ter novamente que fazer uso dessa poupança a fim de manter os custos do veículo desgastado pelo uso intenso e pela baixa remuneração auferida como motorista.

\section{Estratégias empresariais mundiais de re-regulamentação}


Em virtude do advento da chamada acumulação flexível de capital, com as crises ocorridas desde os anos 1970 e com o aumento da produtividade nas indústrias do transporte e das comunicações, há em curso também uma readequação mundial das regulações estatais de compra e venda da força de trabalho. De acordo com os organismos globais de análise dessas regulações, em todos os países que realizaram reformas trabalhistas nas últimas décadas pôde ser observado o mesmo sentido de desregulamentação dos contratos formais de trabalho e de instituição de maior liberdade de mercado para os empresários recrutarem e, em especial, demitirem os trabalhadores (ILO, 2015). Em decorrência desses processos, o tempo médio de permanência no emprego estaria diminuindo em todos os países que produzem e divulgam dados a respeito, ainda que em ritmos diferentes, a partir de parâmetros historicamente distantes e sob processos também distintos (Felix, 2018; Felix, 2019). O Brasil e outros países latino-americanos, em particular, modificaram significativamente legislações estatais que sintetizavam pactos laborais estabelecidos desde os anos 1940 (ILO, 2015; DIEESE, 2017a; DIEESE, 2017b). Tais alterações, por suposto, implicam mudanças significativas na esfera do trabalho e na reprodução social dos trabalhadores em geral.

Para tanto, algumas empresas transnacionais adotaram campanhas e estratégias internacionais incisivas, associando militância e ativismo político-empresarial, ação ilegal e fomento de mudança das regulações por meio da criação de fatos consumados no mercado.

A Uber, em particular, foi uma dessas empresas, cuja atuação no Brasil privilegiou a difusão de seus aplicativos e o recrutamento de usuários para os mesmos, oferecendo preços abaixo dos que eram oferecidos pelos serviços de taxi ou outros já regulamentados para os clientes enquanto, ao mesmo tempo, proporcionava possibilidade de rendimento imediato para os trabalhadores demitidos, desempregados ou em situações e postos de trabalho precários e mal remunerados. Junto à essa difusão, em um primeiro momento, contratou escritórios de advocacia para dar assistência eventual aos motoristas e, tal como as demais plataformas, advogou em prol da liberdade de mercado e da relação de compra e venda dos serviços de sua plataforma pela internet tanto para clientes quanto para os motoristas e entregadores. Certos casos, associou-se a empresas locais, que, vinculadas ao empresariado regional, também ofereceram os mesmos serviços por meio de plataformas virtuais. Frente a essas, a Uber adotou diversas estratégias, variando desde o dumping e a compra das outras empresas, até a aceitação de concorrência com fins de ampliação do mercado, subordinando aqueles que dominavam as redes anteriores de serviços de transporte privado de passageiros e, dessa forma, constituindo uma cadeia de pequenos, médios e grandes capitalistas regionais dependentes. Uma vez 
assim estabelecida localmente, a Uber e demais empresas promoveram negociações com os agentes políticos para a adequação estatal das suas operações, que, em geral, foram bem sucedidas.

No Brasil, adotando essas estratégias, a Uber rapidamente se propagou como a plataforma de transportes mais utilizada e difundiu massivamente seus serviços nas principais cidades, como Rio de Janeiro e São Paulo. Com a sua expansão, as disputas legais locais a respeito da sua atuação foram levadas aos tribunais e, dada a dinâmica dos mesmos, ao longo das decisões preliminares que garantiram as suas operações, também à esfera política dos organismos executivos e legislativos regionais e nacionais. Assim, em 2016, foi plenamente regularizada na cidade de São Paulo. Essa foi a primeira cidade a legalizar a Uber e era, justamente, naquele momento, segundo os dados da empresa, aquela em que mais se vendia os seus serviços no mundo. Em seguida, em 2017, após a já mencionada visita de seus dirigentes mundiais ao Brasil, atendida por ministros de Estado, houve também o pleno reconhecimento político e legal nacional. No contexto atual, a Uber e similares operam regularmente em todas as grandes e médias cidades brasileiras.

Mesmo em outros países nos quais a informalidade ou a existência de formas de trabalho não reguladas pelo Estado é menor, como é o caso dos países centrais, a Uber e outras plataformas têm empregado estratégias militantes similares. Na Inglaterra, após longo embate no judiciário, reconheceuse o vínculo de trabalho dos motoristas com a empresa e suas operações foram plenamente regularizadas frente a um mercado de trabalho no qual já, inclusive, se previa o denominado Zero-hour Contract, ou seja, a contratação dos trabalhadores sem jornada fixa e com remuneração apenas pelas horas solicitadas pelas empresas. Similarmente, nos EUA, em que também impera liberdade de mercado formal, as disputas judiciais envolvem reconhecimento ou não do vínculo de emprego. Tal questão ainda vem sendo debatido nas diversas jurisdições e estados federados. Na Espanha, recentemente, houve processo semelhante e as plataformas foram obrigadas a reconhecer o vínculo empregatício. Todavia, tiveram suas operações regularizadas na forma de compra e exploração da força de trabalho que adotam por meio dos aplicativos.

Ainda assim, a militância político-empresarial da Uber e plataformas associadas advogam para que não seja reconhecido vínculo empregatício algum entre os trabalhadores e as empresas e que, nesse sentido, os custos operacionais sejam menores nos países em que vendem os seus serviços E isso é o que ocorre na maioria dos países atualmente. Em 2018, por exemplo, um estudo realizado por advogados em 40 países indicava que em mais da metade deles não havia qualquer chance desses trabalhadores terem vínculos reconhecidos na legislação trabalhista formal e nos demais, em sua maior parte, essa chance ainda dependia da apresentação de muitos fatores comprobatórios por parte dos trabalhadores (Ius Laboris, 2018). E, mesmo entre essa minoria de países em que há possibilidade de 
enquadramento formal, a formalização laboral prevê instrumentos de terceirização alheios a leis trabalhistas, de maneira praticamente idêntica aos demais países em que as empresas também foram plenamente bem-sucedidas nas suas estratégias de mercado. É o caso da Itália, por exemplo, em que as empresas adotaram o que ficou abreviado como "co-co-co" (Contrato por Colaboração Continuada em um Projeto) $)^{8}$.

\section{Novas e velhas formas de controle e resistência}

O uso de plataformas digitais para a oferta e a venda dos serviços de transporte por parte das empresas utiliza informação por satélite em sistemas que têm acesso a dados estratégicos minuciosos por meio dos telefones celulares. Nesse caso, em termos informacionais, tais dados podem ser utilizados tanto para as operações de mercado propriamente ditas - informações de compra e venda das mercadorias, como preferências, perfis de compras, perfis de clientes etc - quanto, também, para as operações de controle da exploração do trabalho - como é o caso da intensidade e dos tempos de trabalho, da aceitação ou não das remunerações etc.

Sendo assim, os sistemas eletrônicos dessas empresas - geralmente elaborados com o emprego das mesmas formas de compra, venda, controle e exploração da força de trabalho de técnicos e engenheiros da computação - dispõem de meios computacionais extremamente aprimorados para gerenciar algoritmicamente os mecanismos de competição de mercado entre os trabalhadores. Com os dados fornecidos a cada vínculo ou conexão dos usuários do sistema, na Uber, por exemplo, é possível ranquear detalhadamente o trabalho dos motoristas, verificando o ritmo, a freqüência e o perfil de cada um e, a partir disso, inserir dispositivos econômicos de interesse da empresa a fim de aumentar os lucros em praticamente todas as atividades que desenvolve.

Esses sistemas estão sendo comumente associados às empresas de aplicativos e ao chamado capitalismo de plataforma, porém seu alcance já é de maior amplitude. Empresas como a Amazon, que controlam considerável parcela do mercado de oferta, venda e entrega de mercadorias pela internet no mundo hoje, dispõem de dispositivos de gerência do trabalho similares não apenas nos sistemas de vendas e transporte, mas também em suas unidades fabris de armazenamento e empacotamento que contam com milhares de trabalhadores. Junto às máquinas, as operações corporais dos trabalhadores

8 Cf. "Luta nos aplicativos: a greve da Foodora" (Passa Palavra, 12/12/2016). 
estão sendo monitoradas com o auxílio de dispositivos que permitem coletar dados individualizados das suas atividades laborais ${ }^{9}$.

Nessas condições, o gerenciamento empresarial dispõe de dados individualizados para maximizar operações clássicas de controle e exploração do trabalho, como é o caso da seleção, avaliação, vigilância, punição, demissão e recontratação dos trabalhadores. Contudo, tais operações são realizadas de maneira difusa e, uma vez diluída a própria compra e venda da força de trabalho em seus mecanismos, a ação social do exército de reserva de trabalhadores à disposição das empresas de aplicativos também se imiscui em situações mais intermitentemente aceleradas e, ao mesmo tempo, permanentes.

No caso da Uber, o sistema de avaliações do/a motorista oferece premiações conforme aumento do número de corridas realizadas por meio do aplicativo, conforme ele/a menos recusa as ofertas de próximas corridas e conforme ele/a recebe melhores notas por parte dos clientes da Uber. Em geral, a oferta do próximo percurso é feito enquanto ele/a ainda termina a corrida anterior. Essas premiações permitem que o/a motorista tenha acesso a mais informações no sistema (como é o caso do destino das próximas corridas), tenha mais opções de gerenciar o próprio deslocamento na cidade e, em especial, que ele/a tenha acesso a ofertas de melhores corridas e/ou a localizações como aeroportos, rodoviárias etc. Embora tais operações não sejam disponíveis para os seus usuários e eles só tenham uma percepção intuitiva das mesmas, é possível que o aplicativo também direcione as chamadas em virtude de outros dados, considerando que praticamente todos os dados dos deslocamentos do condutor e dos clientes são monitorados depois que eles instalam o aplicativo em seus celulares. Por outro lado, o sistema também impõe cancelamentos, suspensões ou bloqueios temporários à conexão dos motoristas conforme eles menos atendam aos interesses da empresa. Em particular, quando eles/as apresentam alta taxa de recusa de ofertas de corridas pelo aplicativo.

Frente a esses dispositivos, por sua vez, os trabalhadores e demais usuários têm empregado formas de resistência tanto individuais quanto coletivas, por meio de sabotagens, paralisações, manifestações de rua e greves regionais, nacionais e internacionais.

As sabotagens envolvem conhecimento e compartilhamento de contra-informação entre os/as trabalhadores. São empregadas várias, por exemplo: técnicas digitais diversas de acesso a informações das chamadas, como local de destino e preço; técnicas para manejo dos direcionamentos geográficos das corridas ofertadas; técnicas para o manejo dos cancelamentos das chamadas aceitas; técnicas para

\footnotetext{
9 Cf. "Amazon's automated employee-tracking system can fire workers based on productivity without ever consulting a human" (Dailymail, 26 April 2019). Junto a essas tecnologias, e com as mesmas implicações, estão sendo aplicadas as pesquisas de qualidade realizadas a cada compra com os clientes dessas empresas (Huws et al., 2019). Em ambos os casos, há maior pressão dos efeitos de uma super-circulação sobre os trabalhadores (Felix, 2018).
} 
informações relativas às filas digitais de motoristas aguardando corridas nos pontos de espera; articulações informais para o manejo da inteligência artificial dos sistemas em geral, a fim de recusar e/ ou de proporcionar mudanças nas remunerações por corrida (oferta e demanda de motoristas em determinadas áreas, bloqueios de chamadas advindas de tarifas promocionais para os clientes etc).

$\mathrm{Na}$ Uber, desde os primeiros anos em que iniciou suas operações nas grandes cidades, a informação a respeito do destino das corridas era desconhecido para a aceitação ou não do/a motorista no momento em que recebia a chamada. Porém, parte dos/as motoristas já dominava uma técnica para acessar essa informação antes de aceitar a corrida, burlando o sistema. Outros/as, utilizavam maneiras de atrasar a busca do cliente até que o mesmo viesse a utilizar o mecanismo de cancelamento, que, caso utilizado pelo motorista, implicaria em alguma sanção ou perda de pontuação/ranqueamento. Em seguida, como essa foi uma reivindicação coletiva e alguns aplicativos similares já forneciam essa informação para os motoristas, a Uber veio a fornecer a região para a qual o cliente quer se dirigir. Os detalhes, porém, ainda permanecem em disputa digital entre a Uber, que os oferta como premiação, e os/as motoristas, que buscam novas maneiras de sabotar o sistema. Outro exemplo é o recurso de seleção por direcionamento das corridas seguintes, que, também após reivindicações coletivas, atualmente a Uber oferece o uso desse dispositivo duas vezes por dia em algumas das grandes cidades brasileiras. Entre aqueles que fazem longas jornadas de trabalho e que estão vinculados a essas empresas por mais tempo, já se desenvolveu e se ensina uma técnica que permite usar tal dispositivo geográfico direcionador mais do que duas vezes ao dia.

Essas sabotagens, porém, enfrentam o aprimoramento contínuo dos sistemas por parte das empresas, que corrigem as falhas e otimizam o uso lucrativo de cada vez mais dados obtidos por meio dos seus aplicativos e, por outro lado, também enfrentam formas de controle consideradas mais antigas, como é o caso do uso de espiões e de infiltrados a serviço da empresa. Alguns motoristas da Uber, por exemplo, relatam que normalmente espiões se apresentam como clientes e usuários para os/as motoristas, buscando ter acesso a essas técnicas e demais informações de interesse gerencial, e que, com os mesmos objetivos, há também motoristas infiltrados nos meios de sociabilidade, agrupação ou mobilização.

Dadas as estratégias de mercado e de autorização estatal adotadas pela Uber, houveram várias manifestações de âmbito regional nas cidades, convocadas por taxistas autônomos e empresas locais, sindicatos e associações diversas, contra a implantação das empresas de aplicativos ou pela sua regularização, assim como por parte dos próprios motoristas, também, em um primeiro momento, em defesa de melhores condições de regularização e, em seguida, junto aos demais entregadores, por melhores condições de trabalho e salários. Tais atos de denúncia, em geral, foram acompanhadas de 
paralisações e de atos de rua, com faixas, cartazes, carreatas, fechamento de estradas, panfletagem para a população e convocações de boicote e de apoio para as reivindicações. No caso do Brasil, essas manifestações ocorreram em praticamente todas as cidades em que a Uber iniciou suas operações, desde o primeiro momento em que seus serviços foram difundidos. Em diversas situações, deram origem a movimentos locais ou regionais específicos e a algumas associações de caráter pró-sindical. Em seguida, foram associações diversas como essas que iniciaram movimentos politicamente mais ambiciosos e, com o apoio de diferentes organizações, fizeram convocações de paralisações e greves de caráter autônomo e internacional.

Em maio de 2019, por exemplo, frente ao anúncio da abertura de ações da Uber na bolsa de valores de Nova York, há a primeira convocação de uma greve mundial, cuja principal pauta era relativa à baixa remuneração da força de trabalho, com a denúncia das péssimas condições oferecidas pela empresa de aplicativo para motoristas em todo o mundo e, por outro lado, também dos preços pagos pelos clientes pelos serviços. Convocada por diversas associações a partir de diferentes regiões dos EUA e de outros países e usando diversos meios de comunicação gratuitos disponíveis na internet, essa veio a ser a primeira grande manifestação de amplitude mundial do chamado capitalismo de plataformas a partir da adesão de milhares de motoristas em diversos países e amplo apoio das mídias alternativas, ativistas, militantes, partidos políticos e dos demais trabalhadores, assim como dos usuários e clientes dessas plataformas ${ }^{10}$. Até onde se tem informação, foi também a primeira greve mundial de uma mesma categoria de trabalhadores convocada de forma autônoma e com o uso dos atuais meios de comunicação de massa, como é o caso das mídias sociais, dos aplicativos de mensagens instantâneas, sites de postagens gratuitas, serviços de traduções automáticas simultâneas etc.

Da mesma forma, em julho de 2020, a partir de convocações feitas por associações diversas no Brasil e através dos mesmos meios que convocaram a greve geral mundial da Uber de 2019, os entregadores de empresas de aplicativos em geral realizaram uma paralisação com ampla adesão nas mais diferentes regiões do país, assim como em outros países, como foi o caso da Argentina, México, Chile, Colômbia etc. A greve logo teve a adesão de movimentos sindicais e políticos variados e foi apoiada na forma de novas divulgações, acesso às mídias vinculadas a esses movimentos e convocações solidárias de boicote às empresas de entrega e transporte por aplicativos.

\section{A luta de classes pode ser "cancelada"?}

\footnotetext{
10 Cf. "Uber driver: "I'm just asking for a livable wage” (CBS News, 08/05/2019); “Uber drivers strike over pay and conditions" (The Guardian, 08/05/2019).
} 
Recentemente, ressaltamos os processos sociais que fundamentariam as condições pelas quais estariam sendo gestadas algumas reivindicações proletárias mundiais relativamente similares e, a partir das mesmas, consideramos a possibilidade de ações políticas unificadas que, eventualmente, poderiam vir a desafiar as teses que associam maior rotatividade à menor poder classista de organização (Felix, 2018). Neste sentido, dentre outros, viemos a pesquisar o cotidiano de parte dos trabalhadores submetidos à uberização, às empresas de aplicativo em geral e, em particular, à própria Uber.

Sendo assim, ressaltamos aqui, em um primeiro momento, alguns aspectos do debate sociológico que envolve o advento do chamado capitalismo de plataforma e as condições de classe que envolvem a produção social da visibilidade dos trabalhadores uberizados. E, em seguida, face às condições de trabalho dos motoristas da Uber e às estratégias empresariais de regularização das empresas que exploram o trabalho por meio de plataformas digitais, analisamos algumas formas de controle e de resistência, como é o caso das sabotagens, das paralisações, manifestações e greves, que, em geral, organizada enquanto categoria laboral, no que se refere à agência política, padecem de limitações e potencialidades não muito diferentes das análises classistas clássicas já relatadas na literatura sobre o movimento operário. No caso dessas últimas greves, porém, dada a característica autônoma frente aos meios de convocação e às direções dos organismos sindicais tradicionais e, em particular, dadas as reivindicações imediatas de caráter internacionalista, há que se analisar ainda o sentido que tomarão frente às manifestações e movimentos anti-globalização de massa até então em $\operatorname{voga} 11$.

Contudo, a análise das potencialidades de ação política dos trabalhadores uberizados, plataformizados e/ou em plataformização implica, metodologicamente, na observação plena das relações sociais de circulação que lhes impõe a acumulação de capital atualmente e que, dentre outros aspectos, aproxima a ponto de indistinguir as situações de exército ativo e de reserva, fenômeno pelo qual, em condições modernas, constitui, efetivamente, condições sociais de possibilidade de constituição política classista, enquanto, por outro lado, desconstitui ou enfraquece a ação política setorial ou fragmentarista. Neste sentido, da mesma forma, em espelho, quanto mais a análise política se afasta desta perspectiva colocada pela morfologia contemporânea de classe, menos ela também

\footnotetext{
11 Em termos das adesões políticas às manifestações contra-hegemônicas de âmbito global, grosso modo, as greves convocadas pelos trabalhadores das empresas de aplicativos só se comparam aos movimentos anti-sistêmicos pósBatalha de Seattle. Contudo, se em 1999 as manifestações se reuniam em torno das convocações à população para a luta contra o livre comércio e as ideologias neoliberais na forma de combate às reuniões dos chefes de Estado e de organismos como o G7, G20, OMC etc, em 2019, as manifestações se reuniram em torno das convocações aos trabalhadores e aos seus apoiadores para a luta contra a exploração do trabalho, as empresas transnacionais de aplicativos e o capitalismo de plataforma na forma de greve mundial. Resta saber se, em virtude das hipóteses que apresentamos a respeito dos processos sociais de constituição ou não de condições proletárias mundiais tais manifestações terão, também, tendências sociais de unificação a partir de reivindicações e horizontes políticos de emancipação de classe e de greve geral mundial.
} 
percebe o que uma determinada situação ou categoria de classe permite sociologicamente no atual momento.

\section{Referências}

ABDELNOUR, S.; BERNARD, S. (2018) Vers un capitalisme de plateforme? La nouvelle revue du travail 13, Available from: http://journals.openedition.org/nrt/3797 (accessed 18 March 2020).

ALVES, G. Trabalho e neodesenvolvimentismo. Marília: Práxis, 2014.

ANTUNES, R. O privilégio da servidão. São Paulo: Bolotempo, 2018.

BRAGA, R. A rebeldia do precariado. São Paulo: Bolotempo, 2017.

CARDOSO DE OLIVEIRA, R. A sociologia do Brasil indígena. Rio de Janeiro/Brasília: Tempo Brasileiro/ Editora da UnB, 1978.

CASANOVA, P. G. De la sociología del poder a la sociología de la explotación: pensar América Latina en el siglo XXI. Bogotá: Siglo del Hombre Editores y Clacso, 2009.

CASTEL, R. As metamorfoses da questão social. Petropolis, Vozes, 1998.

CHAVES JR. et al. Trabalhadores Plataformizados e o Acesso à Justiça Pela Via dos Direitos. Belo Horizonte: Expert, 2021.

CHESNAIS, F. "A mundialização do exército industrial de reserva". O Comuneiro, n.3, setembro 2006. Disponível em: http://www.ocomuneiro.com/nr03_01_francois.htm.

DIEESE, Boletim de Conjuntura, No. 22, mai, 2020a.

DIEESE, Boletim Emprego em Pauta, No. 17, dez. 2020 b.

DIEESE. "A reforma trabalhista e os impactos para as relações de trabalho no Brasil”. São Paulo: DIESE, 2017a.

DIEESE. “Impactos da Lei 13429/17”. São Paulo: DIESSE, 2017b.

FELIX, G. “Circulación y superexplotación del trabajo”. Sociología del Trabajo, v. 92, p. 87-105, 2018.

FELIX, G. "Mate todos eles! Amazonização do trabalho, consenso bolsonarista e algumas distopias políticas do primeiro de maio no Brasil". Kaos en la Red, 06 mai 2020. Disponível em: https://passapalavra.info/ 2020/05/131645/

FELIX, G. "Super-Circulation: Towards a Political Economy of Platformisation". Critical Sociology, 46(7-8):1221-1232; 2020.

FELIX, G. Mobilidade e superexploração do trabalho: o enigma da circulação. Rio de Janeiro: FAPESP/ Lamparina, 2019. 352p.

FELIX, G. "Aportes da teoria marxista da dependência para a análise da agropecuária e da indústria da mineração." SocArXiv. (May 2021). Available from: 10.31235/osf.io/6jy8g

FELIX, G.; SOTELO VALENCIA, A. "A superexploração do trabalho: uma perspectiva da precariedade e da condição proletária a partir da teoria da dependência". Astrolabio Nueva Época, 23, p. 1-26, 2019.

FOSTER; MCCHESNEY; JONNA. "The Global Reserve Army of Labor and the New Imperialism". Monthly Review, Volume 63, Issue 06 (November), 2011. 
GUNDER FRANK, A. "A agricultura brasileira: capitalismo e mito do feudalismo" [1964]. In: Stedile (org). A questão agrária no Brasil. São Paulo: Expressão Popular, 2005.

HARVEY, D. Condição pós-moderna. São Paulo: Loyola, 2008.

HUWS, U. et al. The platformisation of work in Europe. Brussels: Foundation for European Progressive Studies, 2019.

INTERNATIONAL LABOUR ORGANIZATION (ILO). "World employment and social outlook 2015: The changing nature of jobs". International Labour Office. Geneva: ILO, $2015 \mathrm{a}$.

INTERNATIONAL LABOUR ORGANIZATION (ILO). "Labour Market reforms since the crisis: drivers and consequences". Geneva: ILO, 2015 b.

INTERNATIONAL LABOUR ORGANIZATION (ILO). Digital Labour Platforms and the Future of Work. Geneva: ILO, 2018.

IUS LABORIS. The gig economy. Brussels: Ius Laboris, 2018.

MAGDOFF, F.; MAGDOFF, H. "Disposable Workers: Today's Reserve Army of Labor”. Monthly Review, vol. 55, n. 11, april 2004.

MARINI, R. M. "Las razones del neodesarrollismo". Revista Mexicana de Sociologia, Ano XL, vol. XL, número extraordinário, 1978.

MARINI, R. M. "Prefácio". In: Sotelo, A. México: dependencia y modernización. Mexico: FCPyS/UNAM/ CELA, 1993.

MARINI, R. M. "Proceso y tendencias de la globalización capitalista". In: Marini; Millán (orgs). La teoría social latinoamericana, t. IV: Cuestiones contemporáneas. México: UNAM/FCPyS/CELA, 1996.

MARINI, R. M. Dialéctica de la dependencia. Mexico DF: Era, 1973.

MARINI, R. M. Subdesarrollo y revolución. México: Siglo XXI Editores, 1974.

NUN, J. Marginalidad y exclusión social. Buenos Aires: FCE, 2001.

PANITCH, L.; ALBO, G. (eds). Beyond digital capitalism, Socialist Register, 2021.

PESOLE, A. et al. Platform workers in Europe. Luxembourg: Publications Office of the European Union, 2018.

SMITH, John. Imperialism in the 21st Century: globalization, super-exploitation and capitalism's final crisis. New York: Monthly Review Press, 2016.

SOEDERBERG, S. "The US Debtfare State and the Credit Card Industry". Antipode. Vol. 45, n. 2, March 2013, pp. 493-512.

SOTELO, A. Los rumbos del trabajo. México D.F.: Miguel Ángel Porrúa, 2012.

SOTELO, A. México: dependencia y modernización. México: Centro de Estudios Latinoamericanos/FCPyS/ UNAM, 1993.

STANDING, G. O precariado: a nova classe perigosa. Belo Horizonte: Autêntica, 2015. 